British Journal of Psychiatry (1994), 164, 855

\title{
A HUNDRED YEARS AGO
}

\section{A Neapolitan private asylum}

I was recently under the necessity of paying daily visits for a month to the Manicomio Fleurent at Naples; and perhaps an account of this establishment may not be uninteresting to readers of the Lancet.

Admission is by a medical certificate, stamped and visé by the municipal authority. A form corresponding to our "statement" is also filled in by the physician and friends. The questions asked are, however, of a much more comprehensive character than in those in the statement - to wit, as to the patient's temperament, habits, education, moral character, sensuality, sobriety, mental overwork, hallucinations (external of the five senses, internal della vita fisica), with many others. The terms range from 500 lire to 100 lire a month. In the first class special the patient has a sittingroom and bedroom, special attendant, "very sumptuous" diet, cigars, and tobacco furnished him, ices every day in summer, and a drive in a two-horse carriage twice a week. In the second class special (350 lire a month) the diet is "sumptuous", the prospectus says; there is a special attendant, and one room furnished and entirely separate, two ices a week in summer, cigarettes, and carriage drive $a$ due cavalli twice a month. In the ordinary first class (220 lire a month) the patient has a private room, and breakfasts, dines, and sups in private. In the second ordinary (160 lire a month) he shares his room with another, and takes his meals at table d'hôte. The third class ordinary (100 lire a month) sleep in a dormitory, and dine in the refectory.

Hydrotherapy, as in most continental asylums, is much in use here, but only by order of the visiting physician, Professor Limoncelli of the University of Naples, and under the supervision of the director. The bathing arrangements, warm, cold, shower, douche, vapour, perineal, \&c., as also the appliances for bathing violent patients, are well contrived. The prolonged use of the warm bath with cold to the head is a favourite method of relief here. There are four rooms with tinted glass - blue, yellow, green, and red. The blue tint has a soft and pleasing effect, and is found beneficial for maniacal patients; and the gay and cheerful effect of the yellow is well adapted for melancholic patients. The eyes are rather pained, however, by the green tint, and the red is never used; the terrible glare of it is maddening in itself, I should say.

Mechanical restraint is used - the camisole, a species of leather muff (for masturbators), and strapping down in the case of very violent cases. Our system of physical restraint, more euphemistically known as non-restraint, is not employed here. "Ah, c'est une espèce de lutte, n'est-ce pas?" said the Director to me, with some irony, when I spoke to him of our so-called non-restraint, and I was quite unable to convince him that a struggle with half a dozen keepers had no element of restraint in it, or that a raving lunatic could be "morally degraded" by being mechanically restrained from injuring himself or others, or that the chances of bruises and broken ribs were not increased tenfold in these struggles, or that human nature being what it is, and keepers keepers, a blow or a kick from a violent patient was not likely to bring about some such retaliation as a little extra "twist" or "pressure" which often led to serious consequences.

The chief fault about the Manicomio Fleurent is the limited space of ground for exercise. Amongst Southern Italians, however, this want is not much felt, and the spacious corridors doubtless afford an equal protection from the summer sun and the winter cold.

Fraser NicOLSON, LRCPED

Reference

Lancet, 21 April 1883. 